\title{
Stress and Depression, Low Religiosity, Social Injustice and Insufficient Rehabilitation Outcomes as Predictors of Frequent Relapse in Drug Dependence
}

\author{
Lee Ching Yin, Abd Razak Zakaria \\ Department of Educational Foundation and Humanities, Faculty of Education, University of Malaya, Kuala Lumpur, Malaysia \\ Email: cyin_ace89@outlook.com, abdrazak@iu.edu
}

How to cite this paper: Yin, L.C. and Zakaria, A.R. (2016) Stress and Depression, Low Religiosity, Social Injustice and Insufficient Rehabilitation Outcomes as Predictors of Frequent Relapse in Drug Dependence. Open Journal of Social Sciences, 4, 194-206. http://dx.doi.org/10.4236/jss.2016.411016

Received: October 11, 2016

Accepted: October 27, 2016

Published: October 30, 2016

Copyright $\odot 2016$ by authors and Scientific Research Publishing Inc. This work is licensed under the Creative Commons Attribution International License (CC BY 4.0).

http://creativecommons.org/licenses/by/4.0/ (c) (i) Open Access

\begin{abstract}
This study was executed to identify stress and depression, low religiosity, social injustice and insufficient rehabilitation outcomes as predictors of frequent relapse in drug dependence among drug addicts in Malaysia. 240 samples were randomly selected from the Cure and Care Rehabilitation in the Serendah district to participate in the survey. The questionnaire was designed to collect information about the participants' demographics including frequency of relapse in drug dependence and the regularity of perceived stress and depression, low religiosity, social injustice and insufficient rehabilitation outcome after being released from detention. The finding shows a combination of stress and depression, insufficient rehabilitation outcome and social injustice increases 2.57 times of the chance of frequent relapse in drug dependence.
\end{abstract}

\section{Keywords}

Relapse, Drug Dependence, Stress and Depression, Low Religiosity, Social Injustice and Insufficient Rehabilitation

\section{Introduction}

The rising rate of social problems in Malaysia has received vast attention from the nation. Fairly or unfairly, these social problems are occasionally associated with substance use (Brunelle, Tremblay, Blanchette-Martin, Gendron \& Tessier, 2014) [1]. Goode (2001) [2] listed 25 most frequent topics of deviance and illegal drug use appeared to be most frequently examined. Illegal drug use creates a certain level of public concern time 
after time as it is a never-ending threatening and damaging social problems. Likewise, the specific drug that attracts public concern has shifted over time, from marijuana in the 1930s, LSD in the 1960s, heroin in the early 1970s, crack cocaine in the later 1980s and more recently, designer drugs such as bath salts and club drugs like ecstasy have become progressively well-known worldwide.

There is a great concern towards drug addiction among youth in Malaysia as such social problem has devastating impacts towards the outbreak of other deviant behaviour. Based on the latest statistics by National Anti-Drug Agencies (NADA, 2013) [3], the total number of detained drug addicts who are sentenced under Section 38B of Dangerous Drugs Act 1952 declined from 23,642 (2010) to 15,101 (2012) but ascended to 20,887 in 2013. Particularly, the number of relapse addicts also showed downturn from 6404 (2010) to 4800 (2012) but an increment to 7406 in 2013. In such manner, noticing that the number of detained drug addicts has disappointed us, the Malaysian government's vision to create a drug addiction free nation in the year of 2015 remains as an inaccessible dream.

The reported statistics showed significant upward movement in 2013 even though Darshan, Chawarski, Schottenfeld \& Balasingam (2013) [4] speculated the decreasing trend of drug users in 2010 to 2012 could be due to medical treatment and harm reduction approaches for drug user have been introduced. However, the number of relapse cases did not continue to plunge yet escalate. Hence, it is certain that Malaysians' vulnerability to drug use has increased. In order to heal the current situation, foremost effort must be taken in identifying the risk factors that will predict frequent relapse among the drug addicts.

\section{Literature Review}

This research focused on indicating the predictors of frequent relapse in drug dependence namely stress and depression, low religiosity, social injustice and insufficient rehabilitation outcome. The problem can be discerned from previous studies which mostly examine the occurrence of substance use (McQueen, 2003 [5], Mirlashari, Demirkol, Salsali, Rafiey, \& Jahanbani 2012 [6], Thompson, 2004, [7], Gomez, Thompson, \& Barczyk., 2010) [8]. Yet, most of these studies did not emphasize the circumstances of substance use which the factors are affecting on it, either it is affecting people to initiate, early initiate, relapse, frequent relapse or long term depending on substance use.

Most of the previous research which study drug dependence focuses on one particular risk or protective factors such as self-efficacy, parenting or social influence (Greenfield, Hufford, Vagge, Muenz, Costello, \& Weiss., 2000 [9], Allsop, Saunders, \& Philips 2000 [10], Mirlashari, et al., 2012 [6], Zimic \& Jukic, 2012 [11], Smirnov, Najman, Hayatbakhsh, Wells, Legosz, \& Kemp,. 2013 [12]). Even there are some studies that focus on more than one factors, these factors are mostly common factors like individual factors, peer influences, and family factors. Therefore, it provided space for the author to investigate a few less-studied risk factors namely stress and depression, low religiosity, social injustice, and insufficient rehabilitation outcome predicts frequent re- 
lapse in drug dependence.

\subsection{Stress and Depression}

Sinha (2008) [13] conducted a study which examined the consequences of stress and drug-related cues on drug craving in alcoholics, cocaine-dependent individuals, and naltrexone-treated, opiate-dependent individuals in recovery. They followed the inpatient treatment-engaged cocaine-and-alcohol dependent individuals after discharge from inpatient treatment for 90 days to evaluate relapse outcomes. For the cocaine group, they found that stress-induced cocaine craving significantly predicted time to cocaine relapse and a high correlation between stress and drug cue-induced drug craving. These data suggest that stress and drug cue-induced distress states produce a similar compulsive drug-seeking state that is associated with relapse vulnerability.

Similarly, Tate, Brown, Glasner, Unrod \& McQuaid (2006) [14] evaluated additive and interactive models of the effects of intense stressful life events, chronic life stressor, and immediate substance availability on substance use following alcohol and drug treatment. 102 veterans meeting Diagnostic and Statistical Manual of Mental Disorder, fourth Edition's criteria for alcohol, cannabis, or stimulant dependence at treatment entry completed quarterly interviews for one year. They found that severe chronic stressors and substance availability predicted an increased risk of relapsing in substance use post-treatment respectively.

Furthermore, Wahler (2015) [15] used multiple regression analysis to examine the role of social disadvantage, economic hardship and perceived stress on follow up addiction severity among 1,099 substance abuse treatment participants referred by the criminal justice system and a comparison group. The findings indicated that unemployment and financial strain could be especially stressful for criminal justice-affected individuals and could, therefore, be related to higher drug addiction severity after treatment.

\subsection{Low Religiosity}

McLeod (2011) [16] conducted a study to describe the lived experiences of alcoholic women in a stable recovery, designated as sustained abstinence for five or more years, who used spirituality as a resource to prevent recidivism. An intentional sample of three women with stable recovery between 6.5 - 20 years, with a mean sobriety of 14.2 years was recruited from Central Alabama Alcoholics Anonymous groups. It was found that the dynamics of spirituality and recidivism prevention to be a multifaceted process rather than a simple cause and effect relationship. The participants expressed Alcoholics Anonymous (AA) as an important safe haven to help them sustain abstinence and as a resource to help them sustain sobriety long until the moment of a personal spiritual awakening completely changed their perceptions and a new dimension of recovery began.

Stewart, Koeske, \& Pringle (2008) [17] administered a study to examine the role of religiosity as a predictor of post-treatment abstinence. The 96 African-American clients who are receiving community-based outpatient alcoholism treatment were interviewed 
during treatment entry and three months later. Results showed that abstainers drank less prior to treatment, had more prior formal treatment and AA involvement, practiced their religion more regularly, and scored greater on measures of both spirituality and extrinsic religiosity.

Mason, Deane, Kelly \& Crowe (2009) [18] examined the relationship between spirituality, religiosity, and self-efficacy with drug and/or alcohol cravings. A cross-sectional survey was completed by 77 male participants aged between 19 and 74 years in an Australian Salvation Army residential rehabilitation service in 2007. It was found that 75 percent of the client expressed that spirituality and religious faith were useful components of the treatment program and multivariate multiple regression analysis identified that spirituality and self-efficacy have significant associations with cravings. Therefore, it is shown that spirituality and religious faith are able to reduce craving, thereby, reduce the risk of relapse.

\subsection{Social Injustice}

Yang, Mamy, Gao \& Xiao (2015) [19] illuminated drug users' experiences during abstinence periods and explored the real-life catalysts and preventions contributing to drug use relapse. Qualitative in-depth interviews were conducted with 20 drug users recruited from a compulsory isolated drug rehabilitation center in Changsha. The interviews were guided by open-ended questions regarding individuals' experiences in drug use initiation, getting addicted, treatment history, social environment, abstinence, and relapse. It was found that during abstinence, their lives were filled with challenges, such as adverse socioeconomic conditions, poor family/social support, interpersonal conflicts, and stigma and discrimination, all of which kept them expelled from mainstream society. Specifically, the police's system of ID card registration, which identifies individuals as drug users, exacerbated already grave situations. Relapse triggers reported by the participants focused primarily on negative feelings, interpersonal conflicts, as well as stressful events which evoked by the challenges congested in their lives.

Furthermore, Miethe, Lu \& Reese (2000) [20] using Braithwaite's theory of reintegrative shame which explain how social control efforts may result in both conformity and deviance as an interpretive framework to examines the relative effectiveness of a specialized drug court in reducing recidivism risks. Contrary to the notions based on its structural similarity to the principles of integrative shaming, they found that risks of recidivism for drug court participants are much higher than comparable offenders processed outside drug court. Field observations and a more detailed examination of daily routines by the researchers explain these unexpected findings by revealing that the drug court is indeed more stigmatizing than conventional courts and is not re-integrative enough in its orientation towards punishment.

On the contrary, Tyler, Sherman, Strang, Barnes \& Woods (2007) [21] used longitudinal data from the drinking-and driving study in the Australian Re-integrative Shaming Experiments (RISE) to evaluate the long-term impacts of re-integrative shaming 
and procedural justice on support for the law and on later recidivism as evaluated through the use of police records and by self-report found that both traditional courtbased prosecution and restorative justice conferences increase support for the law and lower the rate of future reoffending when the engage the social psychological means of re-integrative shaming and procedural justice.

\subsection{Insufficient Rehabilitation Outcome}

Ismail (2001) [22] who studies the effectiveness of Malaysian Anti-Drug policy found that drug problem remains critical due to the lack of enforcement and rehabilitation. This resulted in the rise of the drug relapse cases and trafficking cases over the last five years. Besides, it was found that factors that mitigated the effectiveness of policy include easy access to drug supply, high relapse cases, trafficking, addiction, congestion in treatment centers, the inactive participation of non-governmental organization.

On the other hand, Gossop, Stewart, Browne \& Marsden (2002) [23] conducted a study to investigates factors associated with abstinence, lapse or relapse to heroin use after residential treatment and, particularly, the extent to which changes in cognitive, avoidance and distraction coping responses were related to heroin use and drug use outcomes among 242 clients from 23 residential programs in the NTORS project. The findings showed that clients who avoided a full relapse to heroin use consistently adopt cognitive, avoidance and distraction coping strategies at follow-up than at intake. This showed that treatment completion was related to better outcome.

Jonson (2010) [24] investigated three central empirical questions that stand at the heart of the mass imprisonment movement: alternative sanction (e.g., probation), incarcerating offenders for longer periods of time, and placement in facilities with harsher conditions (e.g., fewer visitations, more restrictions) affects recidivism. In order to address these research questions, he used meta-analytic techniques to complete a quantitative synthesis of 85 research studies. Results indicated that when examining the impact of non-custodial and custodial sanctions on post-release reoffending, a 14 percent rise in recidivism was found for those sentenced to custodial sanctions compared to non-custodial sanctions. Likewise, placement in harsher prison conditions was associated with a 15 percent increase in post-release criminal behaviour, failing to provide support for the specific deterrent argument. However, only the analyses examining the impact of length of sentence period showed a deterrent effect, with longer sentences associated with a 5 percent decrease in recidivism.

\section{Research Objective}

The objective of this research is to identify the extent to which stress and depression, low religiosity, social injustice and insufficient rehabilitation outcome predict the frequent relapse in drug dependence among addicts in Malaysia. Researcher intended to discern how the magnitude of predictors individually and in combination predicts the relapse frequency among addicts. In such, the outcome will not only reveal the strongest predictor of frequent relapse in drug dependence, but also disclose the significance 
of the combination of four predictors in predicting relapse frequency among addicts in Malaysia.

\section{Methodology}

The research methodology selected will be explained in order to answer the research questions that were made: To what extent do stress and depression, low religiosity, social injustice, and insufficient rehabilitation outcome predicts the frequent relapse in drug dependence? Aspects of the methodology will be interpreted on research design, instrument, samples and analysis method.

\subsection{Research Design}

This research employed the quantitative methods of data collecting and analysis. The study was conducted through survey method using questionnaires to gather data. Researcher obtained participants' verbal informed consent beforehand which includes providing adequate information allowing an informed decision about participation in the investigation, easing participants' understanding of the information and obtaining participants' voluntary agreement to participate. The working design used in this study refers to the steps in conducting survey research. This design was chosen based on the size of the population and thereby descriptive and inferential analysis was also chosen.

\subsection{Research Instrument}

In the process of research instrument construction, it was first started by determining the dependent variables and independent variables based on the objective and research question that have been established. Since the focus of this study is to examine stress and depression, low religiosity, social injustice and insufficient rehabilitation outcome as predictors of frequent relapse in drug dependence, the independent variables are the perceived stress and depression, religiosity, social injustice and rehabilitation outcome. On the other hand, the dependent variable is the frequency of relapse.

In order to build a fitting instrument, researcher adopted items from a large number of previous researches. The first section was constructed to collect data of participants' background including demographics and frequency of relapse in drug dependence. Items that are built in this section are single item selections. The second section contains items that described occurrences and circumstances based on the predictors in this study occurred on them after every detention. Six items were built to each component, which makes a total of 24 closed-ended questions. All items were constructed based on Likert-type item which being arranged according to the agreement from "Never", "Rarely", "Not Sure", “Often" and "Very Often". Besides, four open-ended questions on the perception of participants about the predictors of frequent relapse in drug dependence were also constructed to support the findings. Reliability of the constructed items had been verified through a pilot test before the instrument were administered to actual the participants. Items with low reliability were removed from the instrument. 


\subsection{Samples}

This research involved 240 male inmates from the Cure and Care Rehabilitation Centre in the Serendah district in the state of Pahang, Malaysia. Sampling procedures in this study is done by setting the sampling frame which is inmates of the selected rehabilitation centre who meets the criteria of able to read and write, has religion and most importantly current detention is not the first time. Then, researcher adopted the simple random sampling in selecting samples from the sampling frame.

\subsection{Data Analysis Method}

The data collected were computed into the Predictive Analytics Software (PASW) version 21 for quantitative analysis. Binary Logistics Regression test is used to estimate the probability of frequent relapse is present given the values of one or more predictors namely stress and depression, low religiosity, social injustice and insufficient rehabilitation outcome. The reason of using Binary Logistics Regression is because the relapse frequency collected from the survey which is in the form of ratio scale was transformed into dichotomy which is frequent relapse or non-frequent relapse. Stepwise procedure was used to explore the effect of each variable that contribute to the regression model and variables do not contribute to the model will be eliminated.

\section{Results}

The descriptive analysis was performed to obtain the information on the participants' demographics namely age, race educational attainment, birth order, marital status and employment status. Table 1 shows the number of respondents by the demographics examined in this study.

Table 1. Number of respondents by demographics.

\begin{tabular}{|c|c|c|c|c|c|c|}
\hline Age & $19-28$ & $29-38$ & $39-48$ & $49-58$ & $59-68$ & Total \\
\hline Frequency & 219 & 6 & 9 & 3 & & 237 \\
\hline Edu. Attainment & Primary & Lower Secondary & Higher Secondary & Diploma/Degree & & Total \\
\hline Birth Order & Only Child & First Born & Middle Born & Last Born & & Total \\
\hline Frequency & 21 & 33 & 158 & 23 & & 235 \\
\hline Marital Stat. & Married & Single & Divorced & Widower/Widow & & Total \\
\hline Frequency of Relapse & $1-2$ times & 3 Times and above & & & & Total \\
\hline Frequency & 117 & 102 & & & & 219 \\
\hline
\end{tabular}


The inferential analysis was performed with the logistic regression in this study $(\mathrm{N}=$ 240) to discover the effects of stress and depression, low religiosity, social injustice and insufficient rehabilitation outcome on the likelihood that participants relapse frequently in drug dependence. It is found that stress and depression, insufficient rehabilitation outcome and social injustice are the predictors of frequent relapse among drug addicts in Malaysia.

Table 2 shows the value of Nagelkerke $\mathrm{R}^{2}$ of step 1 is 0.260 . This explains that 26 percent of frequent relapse is due to the predictor of stress and depression. Step 1 also shows that stress and depression are the main determinants contributing to frequent relapse. The value of Nagelkerke $\mathrm{R}^{2}$ of step 2 shows that 38.9 percent of frequent relapse is due to a combination of stress and depression and insufficient rehabilitation outcome. In step 3, the value of Nagelkerke $\mathrm{R}^{2} 0.416$ shows a 41.6 percent of frequent relapse is due to a combination of stress and depression, insufficient rehabilitation outcome and social injustice.

Table 3 shows, In this study, 64.7 percent were correctly classified as the frequent relapse group (relapse frequency 3 times and above) and 80.3 percent for the less frequent relapse group (relapse frequency between 1 to 2 times) in step 1. Overall 73.1 percent correctly classified in step 1 . In step 2, 64.7 percent were correctly classified as the frequent relapse group and 80.3 percent for the less frequent relapse group. Overall

Table 2. Model summary of predictors on frequent relapse as dependent variable.

\begin{tabular}{cccc}
\hline Step & -2 Log likelihood & Cox \& Snell R Square & Nagelkerke R Square \\
\hline 1 & 255.116 & 0.195 & 0.260 \\
2 & 227.053 & 0.292 & 0.389 \\
3 & 220.876 & 0.311 & 0.416 \\
\hline
\end{tabular}

Table 3. Classification table of binary logistic regression for frequent relapse.

\begin{tabular}{|c|c|c|c|c|}
\hline & \multirow{3}{*}{ Observed } & \multicolumn{3}{|c|}{ Predicted } \\
\hline & & \multicolumn{2}{|c|}{ Relapse_1 } & \multirow{2}{*}{ Percentage Correct } \\
\hline & & $1-2$ & $3-21$ & \\
\hline \multirow{3}{*}{ Step 1} & $1-2$ times & 94 & 23 & 80.3 \\
\hline & 3 times above & 36 & 66 & 64.7 \\
\hline & Overall Percentage & & & 73.1 \\
\hline \multirow{3}{*}{ Step 2} & 1 - 2 times & 94 & 23 & 80.3 \\
\hline & 3 times above & 36 & 66 & 64.7 \\
\hline & Overall Percentage & & & 73.1 \\
\hline \multirow{2}{*}{ Step 3} & 1-2 times & 80 & 37 & 68.4 \\
\hline & Overall Percentage & & & 71.2 \\
\hline
\end{tabular}

a. The cut value is 0.500 . 
73.1 percent correctly classified in step 2. Lastly, in step 3, 74.5 percent were correctly classified as the frequent relapse group and 68.4 percent for the less frequent relapse group. Overall, 71.2 percent correctly classified in step 3.

Omnibus Test of Model Coefficients result is shown in Table 4. The results of the test show that the three Binary Logistic Regression Steps, which were developed by frequent relapse and predictors (stress and depression, insufficient rehabilitation outcome and social injustice) are significant at the level of $p<0.05$. The three predictors of relapse are factors that contribute to the frequent relapse of drug dependence. Chi-square test results can be summarized as follows:

Table 5 shows the variables in the equation of Binary Logistic Regression. The S.E. $<$ 2.0, therefore multi-collinearity does not exist. In Step 1, Wald $=41.79, p<0.05$ for Stress and Depression indicates that it is a significant predictor that increases the chance of frequent relapse, with OR $[\operatorname{Exp}(B)]=7.5$, it increases 7.5 times of the chance of frequent relapse in drug dependence, which is 3 times and above. When Insufficient

Table 4. Omnibus tests of model coefficients of binary logistic regression for frequent relapse.

\begin{tabular}{lcccc}
\hline & & Chi-square & df & Sig. \\
\hline \multirow{2}{*}{ Step 1 } & Step & 47.454 & 1 & 0.000 \\
& Block & 47.454 & 1 & 0.000 \\
& Model & 47.454 & 1 & 0.000 \\
Step 2 & Step & 28.063 & 1 & 0.000 \\
& Block & 75.517 & 2 & 0.000 \\
& Model & 75.517 & 2 & 0.000 \\
Step 3 & Step & 6.177 & 1 & 0.023 \\
& Block & 81.694 & 3 & 0.000 \\
\hline
\end{tabular}

Step 1: Chi-Square $=47.454, p<0.05$. Step 2: Chi-Square $=75.517, p<0.05$. Step 3: Chi-Square $=81.694, p<0.05$.

Table 5. Variables in the equation of binary logistic regression for frequent relapse.

\begin{tabular}{lccccccc}
\hline & & B & S.E. & Wald & df & Sig. & Exp(B) \\
\hline \multirow{2}{*}{ Step $1^{\text {a }}$} & SDR & 2.014 & 0.312 & 41.794 & 1 & 0.000 & 7.493 \\
& Constant & -2.974 & 0.461 & 41.654 & 1 & 0.000 & 0.051 \\
& SDR & 1.750 & 0.334 & 27.416 & 1 & 0.000 & 5.756 \\
Step 2 & RR & 1.685 & 0.327 & 26.519 & 1 & 0.000 & 1.467 \\
& Constant & -0.072 & 0.695 & 5.206 & 1 & 0.015 & 0.331 \\
& SDR & 1.445 & 0.355 & 16.598 & 1 & 0.000 & 4.241 \\
& SIR & 0.944 & 0.383 & 6.082 & 1 & 0.014 & 2.570 \\
& Rtep 3 & 1.555 & 0.334 & 21.667 & 1 & 0.000 & 1.672 \\
& Constant & -1.421 & 0.899 & 2.499 & 1 & 0.114 & 0.241 \\
\hline
\end{tabular}

a. Variable(s) entered on step 1: SDR. b. Variable(s) entered on step 2: RR. c. Variable(s) entered on step 3: SIR. 
Rehabilitation Outcome are entered into step 2, Wald $=26.52, p<0.05$ for Insufficient Rehabilitation Outcome indicates that it is a significant predictor that increase the chance of frequent relapse in deviants, with $\mathrm{OR}[\operatorname{Exp}(\mathrm{B})]=1.47$, a combination of Stress and Depression and Insufficient Rehabilitation Outcome increases 1.47 times of the chance of frequent relapse in drug dependence, 3 times and above of relapse. In step 3 , Wald $=6.082, p<0.05$ for Social Injustice indicates that it is a significant predictor that increase the chance of frequent relapse in drug dependence, with OR $[\operatorname{Exp}(B)]=$ 2.57, a combination of Stress and Depression, Insufficient Rehabilitation Outcome and Social Injustice increases 2.57 times of the chance of frequent relapse in drug dependence, 3 times and above of relapse.

\section{Discussion}

Of all the predictors of frequent relapse investigated in this study, stress and depression were found to be the crucial determinants to frequent relapse. This is to say that the difficulties and dilemma encountered after detention contribute the most to recurrent relapse. This can be explained where a lot of stressful events can happen after detention, for instance, financial incompetence, unemployment, and unsupportive family. These strains provoke some individuals to come out with ways that they can resolve their difficulties without using the ordinary means of obtaining them. Certainly, this is often through again criminal activities. This is accordance with the finding of Wahler (2015) [15] and Joshua (2015) [25] who proven that relapse induced by stress. Moreover, insufficient rehabilitation outcome was found as second core predictor of frequent relapse. Unemployable vocational skills, unsupportive employment model, ineffective rehabilitation, and unaltered behaviour are issues in rehabilitation or correctional system that lead to high rates of relapse among deviants. These issues have a direct effect on unemployment after release and it could lead to other risk factors or relapse. This result is conformity with Jonson (2010) [24] who indicated a lack of enforcement and effective policy, as well as imprisonment somehow, was associated with an increase in recidivism.

Social injustice was also found as the third predictor of frequent relapse among drug addicts. As Merton's theory presumes deviance will occur if society encourages it by pressuring individuals to commit it. Hence, former convicts tend to re-offend as they do not find any value of themselves from the society after detention. This finding is supported by Kitaria (2014) [26], who found that stigmatization, labelling, shame and guilt correlated with recidivism. Lastly, religious factors were not found predictors of frequent relapse. A greater amount of relapsed inmates reported consistent religious practice and retained religious beliefs after detention. Thus, high rate of recidivism has an irrelative correlation to religiosity after detention most probably is because of strong and serious spiritual and religious practices system have been implemented in the correctional system of Malaysia. This finding is supported by O'Connor \& Duncan (2011) [27] who emphasized that the humanist, spiritual and religious practice need to be integrated nearly into the programming and treatment aspects of the process of correc- 
tional to ensure desistance among inmates.

\section{Conclusions}

The main intention of this study is to scrutinize the predictors of frequent relapse in drug dependence. It is at high priority to identify the extent to which stress and depression, low religiosity, social injustice and insufficient rehabilitation outcome predict frequent relapse in drug dependence among addicts in Malaysia considering that the upsurge of relapse cases among drug addicts is causing a great concern among the community. The finding exhibits stress and depression, insufficient rehabilitation outcome and social injustice are the predictors of frequent relapse among drug addicts in Malaysia. A combination of Stress and Depression, Insufficient Rehabilitation Outcome and Social Injustice increases 2.57 times of the chance of frequent relapse in drug dependence.

The finding of this study would be useful to all members of the community to work hand in hand to assure deviance decline in the community. It is important to notify the people in the community to be supportive towards those who are eager to rectify their previous mistakes and sincere to return to the right path. This is because social injustice from the society will as well create stress and depression to ex-offenders that will lead them back to the old path. Also, educational institutions are indeed holding the role to educate future generations who are more forgiving and sparing in terms of giving chances to people who are keen to amend the mistake made in the past and wish to return to the community. Further, the finding will also enlighten the National Anti-Drug Agencies and Malaysia Prison Department about the limitations of the rehabilitation that lead to high post-retention relapse. Discoveries of the research will inform the effectiveness of policies and practices implemented in terms of rehabilitation programs and religious cultivation in rehabilitation centres and prisons. It is crucial to enforce persuasive programs in order to rehabilitate the inmates efficiently in the retained period.

One of the limitations of this study is the gender of participants due to the geographical constraint. It is suggested to involve female participants, hence to enlarge the sample size in the future study. After all, further examination on drug addicts' religiosity as a protective factor for frequent relapse in drug dependence is significant since it was found that low religiosity is not the predictor of frequent relapse. Hence, it is possible to recognize the strength of religion to prevent frequent relapse among drug addicts in Malaysia.

\section{Conflict of Interest Declaration}

Authors declare there is no conflict of interests with this study, the authorship and the publication of this paper.

\section{References}

[1] Brunelle, N., Tremblay, J., Blanchette-Martin, N., Gendron, A. and Tessier, M. (2014) Rela- 
tionships between Drug and Delinquency in Adolescence: Influence of Gender and Victimization Experiences. Journal of Child \& Adolescent Substance Abuse, 23, 19-28. https:/doi.org/10.1080/1067828X.2012.735488

[2] Goode, E. (2001) Deviant Behaviour. 6th Edition, Prentice Hall, Upper Saddle River.

[3] National Anti-Drug Agency (2013) Bukumaklumatdadah 2013. Ministry of Home Affairs, Putrajaya.

[4] Darshan, S., Chawarski, M. C., Schottenfeld, R. and Balasingam, V. (2013) Substance Abuse and the HIV Situation in Malaysia. Journal of Food and Drug Analysis, 21, S46-S51. https:/doi.org/10.1016/j.jfda.2013.09.033

[5] McQueen, A., Getz, J.G. and Bray, J.H. (2003) Acculturation, Substance Use, and Deviant Behaviour: Examining Separation and Family Conflict as Mediators. Child Development, 74, 1737-1750. https:/doi.org/10.1046/j.1467-8624.2003.00635.x

[6] Mirlashari, J., Demirkol, A., Salsali, M., Rafiey, H. and Jahanbani, J. (2012) Early Childhood Experiences, Parenting and the Process of Drug Dependency among Young People in Tehran, Iran. Drug and Alcohol Review, 31, 461-468. https:/doi.org/10.1111/j.1465-3362.2011.00384.x

[7] Thompson, S.J. (2004) Risk/Protective Factors Associated with Substance Use among Runaway/Homeless Youth Utilizing Emergency Shelter Services Nationwide. Substance Abuse, 25, 13-27. https:/doi.org/10.1300/J465v25n03 02

[8] Gomez, R., Thompson, S. J. and Barczyk, A.N. (2010) Factors Associated with Substance Use among Homeless Young Adults. Substance Abuse, 31, 24-34.

https:/doi.org/10.1080/08897070903442566

[9] Greenfield, S.F., Hufford, M.R., Vagge, L.M., Muenz, L.R., Costello, M.E. and Weiss, R.D. (2000) The Relationship of Self-Efficacy Expectancies to Relapse Among Alcohol Dependent Men and Women: A Prospective Study. Journal of Studies on Alcohol, 61, 345-351. https:/doi.org/10.15288/jsa.2000.61.345

[10] Allsop, S., Saunders, B. and Philips, M. (2000) The Process of Relapse in Severely Dependent Male Problem Drinkers. Addiction, 95, 95-106. https:/doi.org/10.1046/j.1360-0443.2000.9519510.x

[11] Zimic, J.I. and Jukic, V. (2012) Familial Risk Factors Favouring Drug Addiction Onset. Journal of Psychoactive Drugs, 44, 173-185. https:/doi.org/10.1080/02791072.2012.685408

[12] Smirnov, A., Najman, J.M., Hayatbakhsh, R., Wells, H., Legosz, M. and Kemp, R. (2013) Young Adults' Recreational Social Environment as a Predictor of Ecstasy Use Initiation: Findings of a Population-Based Prospective Study. Society for the Study of Addiction, 108, 1809-1817. https:/doi.org/10.1111/add.12239

[13] Sinha, R. (2008) Chronic Stress, Drug Use, and Vulnerability to Addiction. Annals of the New York Academy of Sciences, 1141, 105-130. https:/doi.org/10.1196/annals.1441.030

[14] Tate, S.R., Brown, S.A., Glasner, S.V., Unrod, M. and McQuaid, J.R. (2006) Chronic Life Stress, Acute Stress Events, and Substance Availability in Relapse. Addiction Research and Theory, 14, 303-322. https:/doi.org/10.1080/16066350500262817

[15] Wahler, E.A. (2015) Social Disadvantage and Economic Hardship as Predictors of Follow-Up Addiction Severity after Substance Abuse Treatment: Does Referral to Treatment by the Criminal Justice System Matter? Alcoholism Treatment Quarterly, 33, 6-27. https:/doi.org/10.1080/07347324.2015.982463

[16] McLeod, J. (2011) Alcoholic Women in Recovery: A Phenomenological Inquiry of Spirituality and Recidivism Prevention. Doctoral Dissertation, the University of Alabama, Birmingham. 
[17] Stewart, C., KOeske, G. and Pringle, J.L. (2008) Religiosity as a Predictor of Successful Post-Treatment Abstinence for African-American Clients. Journal of Social Work Practice in the Addictions, 7, 75-92. https:/doi.org/10.1300/J160v07n04 05

[18] Mason, S.J., Deane, F.P., Kelly, P.J. and Crowe, T.P. (2009) Do Spiritual and Religiosity Help the Management of Cravings on Substance Abuse Treatment. Substance Use \& Misuse, 44, 1926-1940. https:/doi.org/10.3109/10826080802486723

[19] Yang, M., Mamy, J., Gao, P. and Xiao, S. (2015) From Abstinence to Relapse: A Preliminary Qualitative Study of Drug Users in a Compulsory Drug Rehabilitation Centre in Changsha, China. PLoS ONE, 10, e0130711. https:/doi.org/10.1371/journal.pone.0130711

[20] Miethe, T.D., Lu, H. and Reese, E. (2000) Reintegrative Shaming and Recidivism Risks in Drug Court: Explanations for Some Unexpected Findings. Crime and Delinquency, 46, 522-541. https:/doi.org/10.1177/0011128700046004006

[21] Tyler, T.R., Sherman, L., Strang, H., Barnes, G.C. and Woods, D. (2007) Reintegrative Shaming, Procedural Justice, and Recidivism: The Engagement of Offenders' Psychological Mechanisms in the Canberra RISE Drinking-and-Driving Experiments. Law \& Society Review, 41, 553-586. https://doi.org/10.1111/j.1540-5893.2007.00314.x

[22] Ismail, H.A. (2001) Kajiankeberkesanandasar anti dadah Malaysia. Unpublished Doctoral dissertation, the University of Malaya, Kuala Lumpur.

[23] Gossop, M., Stewart, D., Browne, N. and Marsden, J. (2002) Factors Associated with Abstinence, Lapse or Relapse to Heroin Use after Residential Treatment: Protective Effect of Coping Responses. Addiction, 97, 1259-1267. https:/doi.org/10.1046/j.1360-0443.2002.00227.x

[24] Jonson, C. (2010) The Impact of Imprisonment on Reoffending: A Meta-Analysis. Electronic Thesis or Dissertation. https://etd.ohiolink.edu/

[25] Joshua, H. (2015) Personality Characteristics, Locus of Control, and Life Stress as Factors in Relapse and Recovery in a Substance Abuse Sample. Master's Thesis, Laurentian University, Sudbury. https://zone.biblio.laurentian.ca/bitstream/10219/2446/1/HULL\%20-\%20THESIS\%20-\%20 Grad\%20Studies 1.pdf

[26] Kitaria, C.K. (2014) Influence of Socio-Economic Factors on Recidivism among Kenyan Prisoners: The Case of Nakuru Main Prison. Master's Thesis, University of Nairobi, Nairobi. http://erepository.uonbi.ac.ke/handle/11295/74036?show=full

[27] O’Connor, T.P. and Duncan, J.B. (2011) The Sociology of Humanist, Spiritual, and Religious Practice in Prison: Supporting Responsively and Desistance from Crime. Religions, 2, 590-610. https:/doi.org/10.3390/rel2040590 
Submit or recommend next manuscript to SCIRP and we will provide best service for you:

Accepting pre-submission inquiries through Email, Facebook, LinkedIn, Twitter, etc. A wide selection of journals (inclusive of 9 subjects, more than 200 journals)

Providing 24-hour high-quality service

User-friendly online submission system

Fair and swift peer-review system

Efficient typesetting and proofreading procedure

Display of the result of downloads and visits, as well as the number of cited articles

Maximum dissemination of your research work

Submit your manuscript at: http://papersubmission.scirp.org/

Orcontact jss@scirp.org 